Article

\title{
Integrated Conductive Hybrid Electrode Materials Based on PPy@ZIF-67-Derived Oxyhydroxide@CFs Composites for Energy Storage
}

\author{
Shuaishuai Yang, Xianhui An and Xueren Qian *
}

Citation: Yang, S.; An, X.; Qian, X. Integrated Conductive Hybrid Electrode Materials Based on PPy@ZIF-67-Derived Oxyhydroxide@CFs Composites for Energy Storage. Polymers 2021, 13, 1082. https://doi.org/10.3390/ polym13071082

Academic Editor: Vito Di Noto

Received: 4 March 2021

Accepted: 24 March 2021

Published: 29 March 2021

Publisher's Note: MDPI stays neutral with regard to jurisdictional claims in published maps and institutional affiliations.

Copyright: (c) 2021 by the authors. Licensee MDPI, Basel, Switzerland. This article is an open access article distributed under the terms and conditions of the Creative Commons Attribution (CC BY) license (https:/ / creativecommons.org/licenses/by/ $4.0 /)$.
Key Laboratory of Bio-Based Material Science \& Technology, Northeast Forestry University, Ministry of Education, Harbin 150040, China; yangshuaishuai10@163.com (S.Y.); anxianh509@163.com (X.A.)

* Correspondence: qianxueren@nefu.edu.cn; Tel.: +86-13304642918

\begin{abstract}
Due to excellent flexibility and hydrophilicity, cellulose fibers ( $\mathrm{CFs}$ ) have become one of the most potential substrate materials in flexible and wearable electronics. In previous work, we prepared cobalt oxyhydroxide with crystal defects modified polypyrrole (PPy)@CFs composites with good electrochemical performance. In this work, we redesigned the crystalline and nanoscale cobalt oxyhydroxide with zeolitic imidazolate frameworks-67 (ZIF-67) as precursor. The results showed that the PPy@ZIF-67 derived cobalt oxyhydroxide@CFs (PZCC) hybrid electrode materials possess far better capacitance of $696.65 \mathrm{~F} \cdot \mathrm{g}^{-1}$ than those of PPy@CFs $\left(308.75 \mathrm{~F} \cdot \mathrm{g}^{-1}\right.$ ) and previous PPy@cobalt oxyhydroxide@CFs (571.3 F.g ${ }^{-1}$ ) at a current density of $0.2 \mathrm{~A} \cdot \mathrm{g}^{-1}$. The PZCC delivers an excellent cyclic stability (capacitance retention of $92.56 \%$ ). Moreover, the PZCC-supercapacitors (SCs) can provide an energy density of $45.51 \mathrm{mWh} \mathrm{cm}{ }^{-3}$ at a power density of $174.67 \mathrm{mWh} \cdot \mathrm{cm}^{-3}$, suggesting the potential application in energy storage area.
\end{abstract}

Keywords: cellulose fibers; ZIF-67 derived cobalt oxyhydroxide; polypyrrole; energy storage

\section{Introduction}

With the rapid development of portable and wearable products, the demand for the flexible energy storage devices will also increase to meet the growth of flexible electronics. Among them, supercapacitors (SCs) with high power density, long cycling life, and excellent charge/discharging ability, have attracted researchers' interests [1-9]. Based on different mechanisms of energy storage, the SCs electrode materials can be divided into electrical double-layer capacitor materials (EDLCs) such as activated carbon [10], carbon nanotubes [11], graphene [12,13], etc. and pseudo-capacitor materials (PCs), such as metal oxides [14,15], metal sulfides [16], conductive polymers [17,18], etc. It should be noted that electrode material is one of the most important components for SCs, which directly determines the electrochemical performances. In practical application, flexible electrode materials should not only meet high efficiency energy storage, but also satisfy low costs and environmental friendliness. Therefore, the development of new high-performance flexible electrode materials has a very important significance for electronic products.

Cellulose fibers (CFs) as superior flexible substrate materials contain rich hydroxyl functional groups and abundant raw material sources, are environmentally friendly, sustainable, light-weight, high-strength, low-cost, recyclable and have good flexibility. Therefore, we select them as substrate materials [19-21]. The porous and rough surface structure provides excellent substrate materials for the loading of electrode materials and the construction of flexible SCs. At the same time, the good wettability of cellulose fiber provides powerful conditions for the electrochemical transfer process between the electrode material and the electrolyte [22]. These unique properties lay the foundation for the construction of flexible SCs.

Compared to the EDLCs, the PCs have higher specific capacitance and energy density due to their reversible redox process. In numerous PCs, conductive polymers (CPs) such 
as polyaniline (PANI) [23], polypyrrole (PPy) [24], polyinode (PIn) [25], and Poly(3,4ethylenedioxythiophene) (PEDOT) [26], have been favored by researchers because of their good electrochemical performance, facile synthesis, and excellent environmental stability. Among them, the PPy with good conductivity and specific capacitance has been widely studied, which mainly focused on the modification of its micromorphology via template method, and combination with other materials, such as PPy/carbon nanotubes (CNTs) [27,28], PPy/graphene oxide (GO) [29,30], PPy / $\mathrm{Ti}_{3} \mathrm{C}_{2} \mathrm{~T}_{\mathrm{x}}$ [31,32], PPy $/ \mathrm{MnO}_{2}$ [33,34], $\mathrm{PPy} / \mathrm{CuS}$ [35], etc. In this work, we proposed to prepare high performance PPy@CFs electrode from the perspective of interface modification between cellulose fibers $(\mathrm{CFs})$ and PPy.

In previous studies, our group investigated the effect of cobalt oxyhydroxide via the $\mathrm{NaBH}_{4}$ reduction method on the electrochemical performance of PPy@CFs composite electrode [36]. The results indicated that the composite electrode exhibited good specific capacitance and cyclic stability. However, we obtained cobalt oxyhydroxide via the method with irregular and amorphous particles. Herein, we conceive to design a cobalt compound with a certain structure as precursor to prepare cobalt oxyhydroxide with high crystallinity of nanometer-scale, which could be more preferred for the electrochemical process of PPy@CFs composites. It is well known that metal-organic frameworks (MOFs) derived materials have aroused widespread concern due to their characteristics, which are organic-inorganic hybrid materials with intramolecular pores formed by self-assembly of organic ligands and metal ions or clusters through coordination bonds. They have many advantages, for example, they are porous, large, and have a specific surface area, making them more conducive to their application of SCs. Therefore, in this paper, we chose ZIF-67 as precursor to prepare cobalt oxyhydroxide with high crystalline and nanoscale in the presence of CFs via the in situ oxidation method, and then coated the PPy on the surface of composites to optimize the electrochemical performance.

\section{Experiment}

\subsection{Materials and Reagents}

Cobalt nitrate, 2-methylimidazole, ammonium persulfate, and ferric chloride were of analytical grade and used as received. Pyrrole monomer was purified by distillation before use. Canada market bleached softwood kraft pulp as CFs source was provided by Mudanjiang Hengfeng Paper Co. Ltd. (Heilongjiang, China) and beaten to $37^{\circ} \mathrm{SR}$ before use.

\subsection{Preparation of ZIF-67 Derived Cobalt Oxyhydroxide@CFs Composites}

The ZIF-67 derived cobalt oxyhydroxide@CFs composites were prepared by a simple in-situ method. Briefly, $0.5 \mathrm{~g}$ of CFs were dispersed in a water or water/methanol system to obtain CFs suspension. Then, the cobalt nitrate $(1 \mathrm{mmol})$ and 2-methylimidazole were added according to the molar ratio of 1:10, and the reaction was carried out at room temperature for $12 \mathrm{~h}$ to obtain ZIF-67@CFs composites. Finally, the ZIF-67 derived cobalt oxyhydroxide@CFs composites were prepared via the oxidation process of ammonium persulfate at $95^{\circ} \mathrm{C}$ for $10 \mathrm{~h}$. The ZIF-67 derived cobalt oxyhydroxide@CFs in water phase was marked as ZCC-1, and the ZIF-67 derived cobalt oxyhydroxide@CFs in water/methanol (volume ratio of 1:1) system was marked as ZCC-2.

\subsection{Preparation of PPy@ZIF-67 Derived Cobalt Oxyhydroxide@CFs Composites}

The typical preparation process was as follows: $0.25 \mathrm{~mL}$ of pyrrole monomer was dispersed in the ZCC- 1 and ZCC-2 suspension, and then $0.973 \mathrm{~g}$ of ferric chloride as initiator was added into the suspension under continuous stirring for $6 \mathrm{~h}$ in an ice-bath system. After the reaction, the mixture was filtrated with distilled water until it was colorless. The PPy@ZIF-67 derived cobalt oxyhydroxide@CFs composites were prepared and noted as PZCC-1 and PZCC-2. 


\subsection{Characterizations}

The morphology of electrode materials was observed by a scanning electron microscope (SEM, SEU 8010). The structure and chemical valence were investigated through X-ray diffraction (XRD, $X^{\prime}$ Pert3 Powder) at a range of $5^{\circ}$ to $80^{\circ}$ with a scan rate of $5^{\circ} \mathrm{min}^{-1}$, fourier transform infrared spectroscopy (FT-IR, Bruker Vertex $80 \mathrm{~V}$ ) with a scanning range of $4000-400 \mathrm{~cm}^{-1}$ at a resolution of $4 \mathrm{~cm}^{-1}$, and X-ray photoelectron spectroscopy (XPS, Thermo ESCALAB 250XI), respectively. Thermal gravimetric analysis (TGA) was performed by STA449 F3 equipment from room temperature to $800^{\circ} \mathrm{C}$ in air with a heating rate of $10^{\circ} \mathrm{C} / \mathrm{min}^{-1}$. The contact angle was measured by JY-82B Kruss DSA equipment.

\subsection{Electrochemical Measurements}

The measurements of cyclic voltammetry (CV), galvanostatic charge-discharge (GCD), and electrochemical impedance spectroscopy (EIS) were carried out in a three-electrode system in $0.6 \mathrm{M} \mathrm{H}_{2} \mathrm{SO}_{4}$ electrolyte. The prepared composite electrodes, Pt electrode, and $\mathrm{Ag} / \mathrm{AgCl}$ in $1 \mathrm{M} \mathrm{KCl}$ were used as working electrode, counter electrode, and reference electrode, respectively. The specific capacitance of composite electrode was calculated from GCD profiles via the equations:

$$
\begin{gathered}
C_{\mathrm{s}}=\frac{\int I d V}{2 m v \Delta V} \\
C_{\mathrm{m}}=\frac{I \Delta t}{m \Delta V}
\end{gathered}
$$

where $C_{\mathrm{s}}$ and $C_{\mathrm{m}}$ are specific capacitance (F. $\mathrm{g}^{-1}$ ) for $\mathrm{CV}$ and GCD profiles, and $m, v, I$, $\Delta V$, and $\Delta t$ represent active mass $(\mathrm{g})$, scan rate $\left(\mathrm{V} \cdot \mathrm{s}^{-1}\right)$, current density $\left(\mathrm{A} \cdot \mathrm{g}^{-1}\right)$, potential window, and discharge time (s), respectively.

In a two-electrode system, the two same electrodes were assembled into the SCs. The energy density and power density were calculated according to the following equations [37]:

$$
\begin{gathered}
C_{\mathrm{a}}=\frac{I \Delta t}{A \Delta V} \\
E=\frac{C_{\mathrm{a}} \times \Delta V^{2}}{2 \times 3600 \times d} \\
P=\frac{3600 E}{\Delta t}
\end{gathered}
$$

where $C_{\mathrm{a}}, I, A, \Delta t$, and $\Delta V$ represent specific capacitance $\left(\mathrm{mF} \cdot \mathrm{cm}^{-2}\right)$, current density (mA $\left.\mathrm{cm}^{-2}\right)$, active area $\left(\mathrm{cm}^{2}\right)$ of two electrodes, discharge time (s), and potential window, respectively, and $E\left(\mathrm{mWh} \cdot \mathrm{cm}^{-3}\right)$ and $P\left(\mathrm{~mW} \cdot \mathrm{cm}^{-3}\right)$ refer to energy density and power density, respectively.

\section{Results and Discussion}

\subsection{Fabrication Process}

The fabrication process of PZCC hybrid electrode materials and photographic images (flexibility, tailorability, conductivity, and strength) are shown in Figure 1. Cellulose with polar hydroxyl and glycoaldehyde acid group makes the surface show electronegativity, which will facilitate the adsorption of $\mathrm{Co}^{2+}$ on the surface of cellulose fibers via electrostatic force. The preparation process for hybrid electrode materials are as follows. Firstly, the CFs suspension, cobalt nitrate, and 2-methylimidazole were mixed in water or water/methanol under a continuous stirring system for $12 \mathrm{~h}$ at room temperature. Secondly, the ZCC was obtained by adding APS as oxidant at $95^{\circ} \mathrm{C}$ for $10 \mathrm{~h}$. Then, a facile in-situ oxidative polymerization method was performed to prepare PZCC hybrid electrode materials under an ice-water bath condition. The chemical bonding force between cobalt oxyhydroxide and PPy can make PPy anchor firmly on cobalt oxyhydroxide@CFs composite. Due to 
the excellent flexibility, tailorability, conductivity, and strength of PZCC hybrid electrode materials, it can be applied in flexible energy storage area.

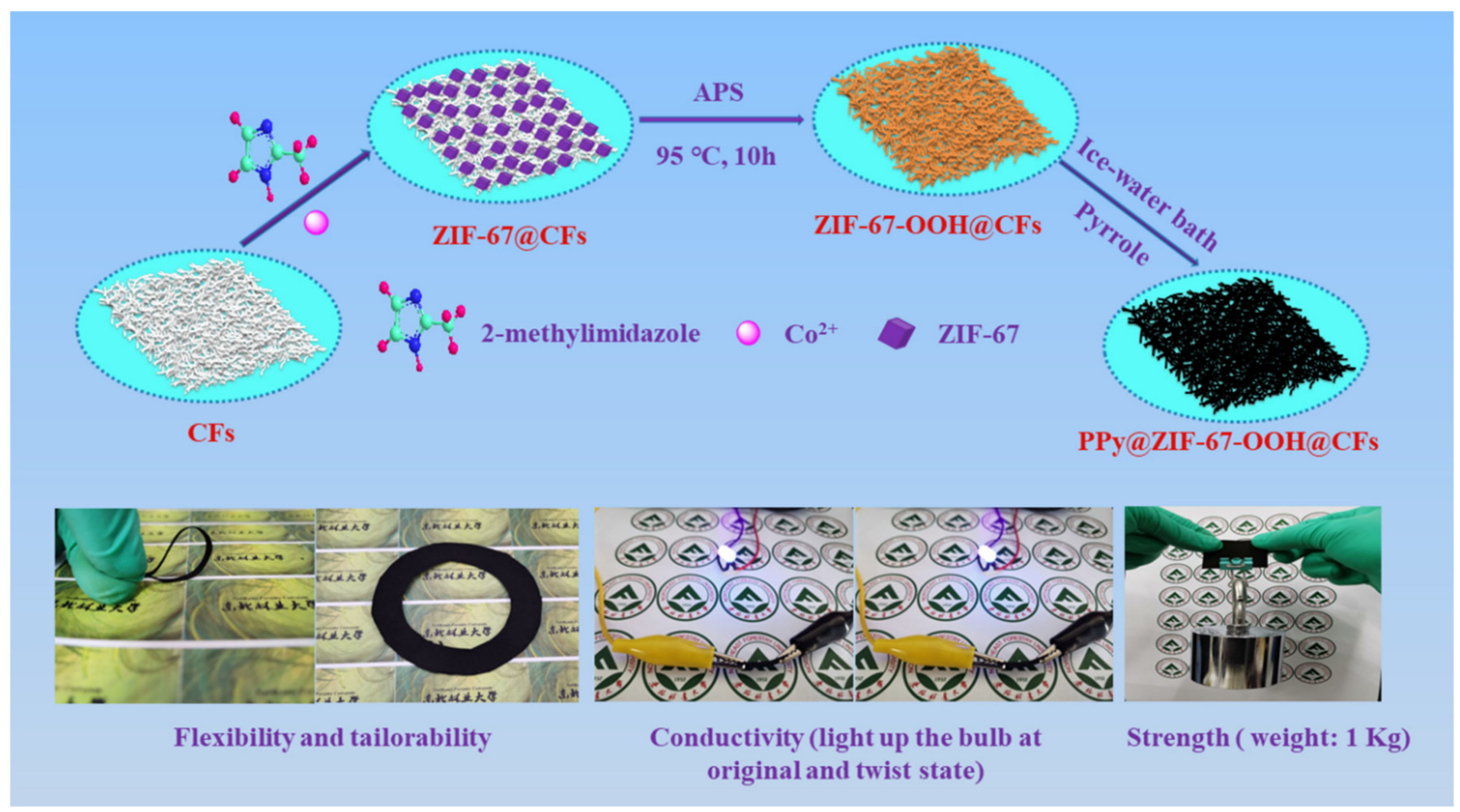

Figure 1. Fabrication process of PPy@ZIF-67 derived cobalt oxyhydroxide@CFs (PZCC) hybrid electrode materials and photographic images (flexibility, tailorability, conductivity, and strength).

\subsection{Characterization Analysis}

The morphology of CFs, PC, ZCC-1, ZCC-2, PZCC-1, and PZCC-2 at low and high magnifications (insert images) are shown in Figure 2. The surface of pure CFs is smooth, with no other substance in Figure 2a. The morphology of PC composite is displayed in Figure $2 b$, where the PPy presents a spherical shape with a diameter of tens of nanometers. Figure 2c,d shows the rough surface of CFs at low magnification, indicating the successful coating of cobalt oxyhydroxide, and it can be seen clearly that some particles are tightly packed and distributed on the surface of CFs at high magnification. The SEM results showed that the successful preparation of cobalt oxyhydroxide particles with regular nanoscale via ZIF-67 as precursor. Compared to PPy@CFs composites, the microscopic morphology of PZCC hybrid electrode material is different, as shown in Figure 2e,f, which is mainly reflected in the change from spherical to short rod morphology. This is more conducive to the charge transfer in the electrochemical process. The elemental mapping of PZCC-2 hybrid electrode material provides more evidence for homogeneous distribution of $\mathrm{Co}$ and $\mathrm{N}$ elements, i.e., cobalt oxyhydroxide and PPy, as shown in Figure $2 \mathrm{~g}-\mathrm{k}$.

To analyze the crystallographic structure of composites, the X-ray diffraction (XRD) test was performed as shown in Figure 3a. The diffraction peaks at $15.6^{\circ}$ and $22.5^{\circ}$ are attributable to the characteristic peaks of CFs. In addition, the characteristic peak of PPy in PC composites is about $22.9^{\circ}$ [38], which coincided with the (002) diffraction plane of CFs. There were some extra peaks in ZCC-2 and PZCC- 2 composites at $18.8^{\circ}, 39.1^{\circ}, 44.3^{\circ}$, and $65.1^{\circ}$, corresponding to the (003), (111), (140), and (002) planes of cobalt oxyhydroxide (ICDD/JCPDS 26-0480, space group: Pbnm (62), a = $4.353 \mathrm{~nm}, \mathrm{~b}=9.402 \mathrm{~nm}, \mathrm{c}=2.840 \mathrm{~nm}$ ). Compared to the previous $\mathrm{NaBH}_{4}$ reduction method, this strategy obtained cobalt oxyhydroxide with higher crystallinity, which may be more helpful for the electrochemical process. The FTIR spectroscopy can be used to confirm the formation of CFs, ZCC-2, and PZCC-2 composites, and reveal the intermolecular binding force (Figure $3 b$ ). The peaks at 3350, 2901, and $1028 \mathrm{~cm}^{-1}$ are attributed to $\mathrm{O}-\mathrm{H}, \mathrm{C}-\mathrm{H}$, and $\mathrm{C}-\mathrm{O}-\mathrm{C}$, respectively [35]. 
The additional peaks at 1637 and $657 \mathrm{~cm}^{-1}$ in the ZCC-2 composite are characteristic peaks of cobalt oxyhydroxide, attributing to $\mathrm{Co}-\mathrm{O}$ and $\mathrm{Co}_{-} \mathrm{O}^{2-}$, respectively $[39,40]$. As for PZCC-2, those at 1543, 1295, 1095, and $964 \mathrm{~cm}^{-1}$ can be assigned to $\mathrm{C}=\mathrm{C}, \mathrm{C}-\mathrm{N}, \mathrm{N}-\mathrm{H}$, and C-C of the PPy ring, respectively [41-44]. The thermal stability and hyrdrophilicity of the composites were characterized by a thermal analyzer and contact angle tester, shown in Figure 3c,d. The results suggest that PZCC-2 hybrid electrode material possesses a better thermal stability, demonstrating that the loading of cobalt oxyhydroxide and PPy is beneficial to its thermal stability. It is well known that the hydrophilicity of electrode material is a crucial parameter in the electrochemical process, only when the electrode material has good hydrophilicity, which allows for better contact with the electrolyte. Based on this opinion, CFs can be well used in the preparation of flexible electrode materials. Figure 3d shows that PZCC-2 has far better hydrophilicity than that of CFs, indicating its potential application in the flexible electronics field.

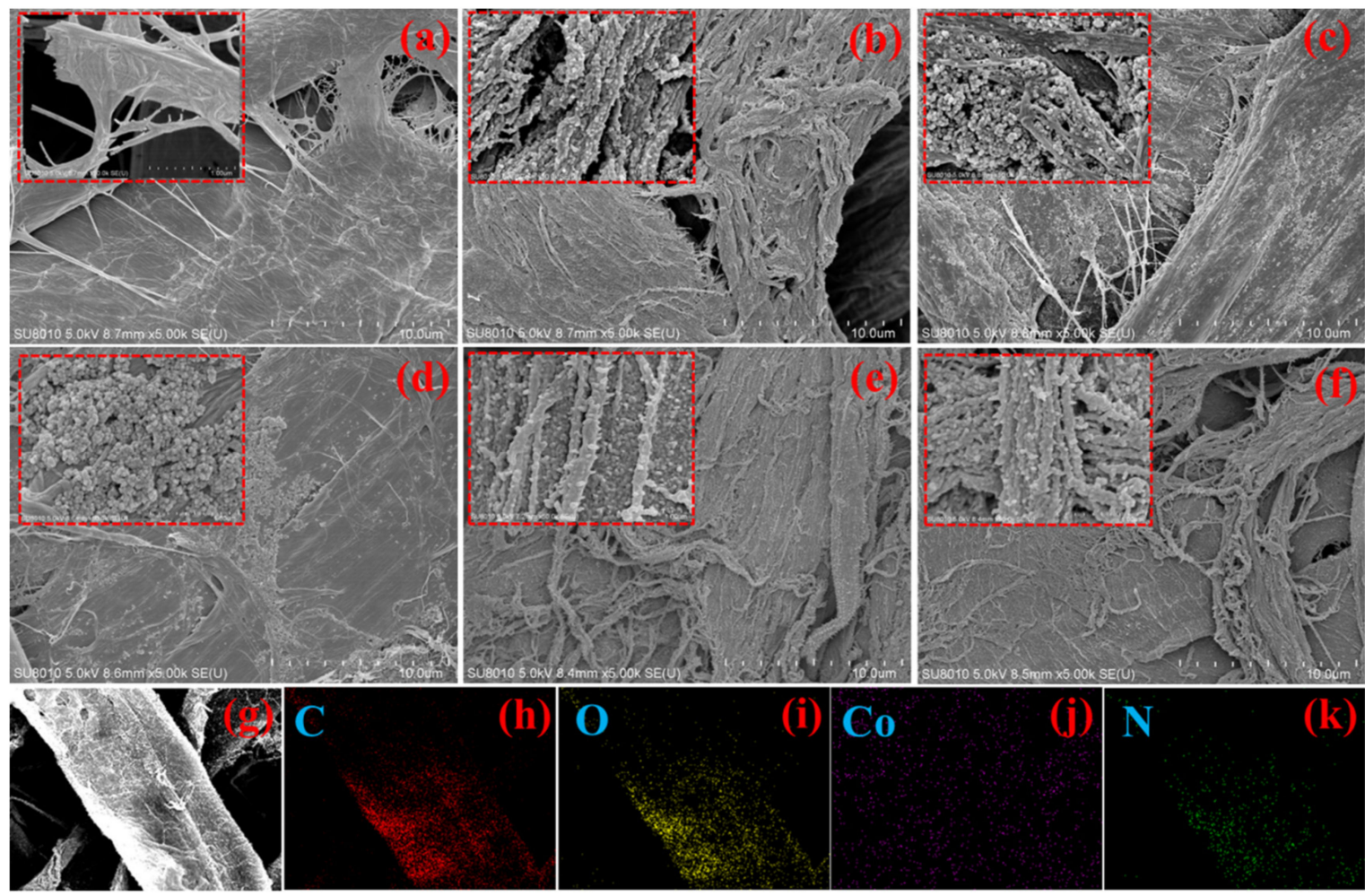

Figure 2. SEM images of cellulose fibers (CFs) (a), pseudo-capacitor materials (PC) (b), ZCC-1 (c), ZCC-2(d), PZCC-1(e), and PZCC-2 (f). Elemental mapping of PZCC-2 (g-k).

The X-ray photoelectron spectroscopy (XPS) was carried out in order to further investigate the elemental composition and chemical properties of composites. As shown in Figure 4, compared to different composites, the C, N, O, Co, elements in PZCC-2 hybrid electrode material originate from CFs ( $\mathrm{C}$ and $\mathrm{O}$ elements), PPy (N element), and cobalt oxyhydroxide (Co element), which indicates that cobalt oxyhydroxide and PPy were successfully loaded on the surface of CFs. As presented in Figure 4e, the Co $2 p$ spectrum is deconvoluted into two main peaks with satellite peak of Co 2p1/2 and Co 2p3/2 at 794.2 and $779.2 \mathrm{eV}$. The XPS Co2p3/2 high-resolution spectrum of PZCC-2 can be fitted into three peaks at $779.6 \mathrm{eV}, 782.4 \mathrm{eV}$, and $789.0 \mathrm{eV}$, attributing to $\mathrm{Co}-\mathrm{O}, \mathrm{Co}-\mathrm{Nx}$, and shake-up satellite peaks, which demonstrates the existence of cobalt oxyhydroxide and Co-N coordination bond simultaneously $[45,46]$. In addition, from Figure $4 \mathrm{f}$, the XPS N 1s spectrum of high-resolution spectrum of PZCC-2 can be fitted into three peaks at $398.5 \mathrm{eV}$ for $=\mathrm{N}-$, $399.3 \mathrm{eV}$ for $-\mathrm{NH}-$, and $401.0 \mathrm{eV}$ for $-\mathrm{NH}^{+}$, suggesting the successful loading of PPy in PZCC-2 hybrid electrode material. 
(a)

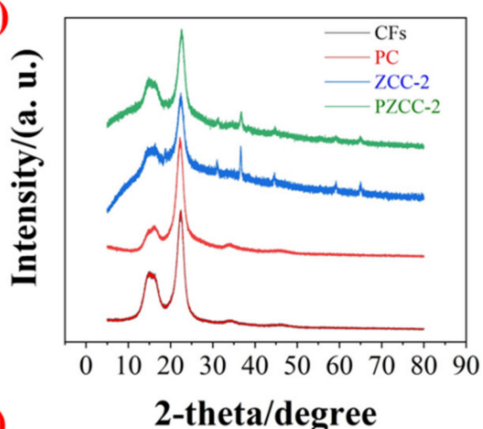

(c)

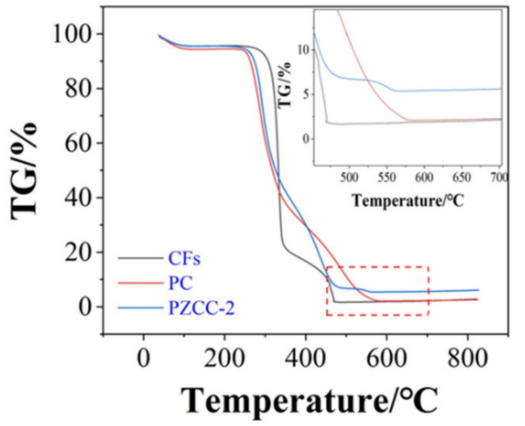

(b)

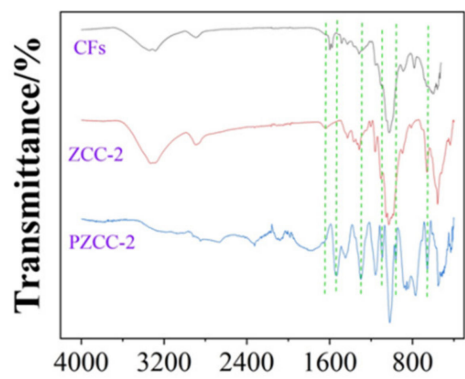

(d)

Wavenumber $/ \mathrm{cm}^{-1}$

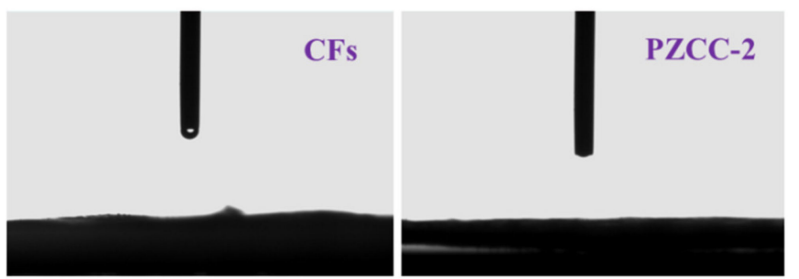

Figure 3. (a) XRD patterns of CFs, PC, ZCC-2, and PZCC-2. (b) FTIR spectra of CFs, ZCC-2, and PZCC-2. (c) TG curves of CFs, PC, and PZCC-2. (d) Hydrophilicity of CFs and PZCC-2.

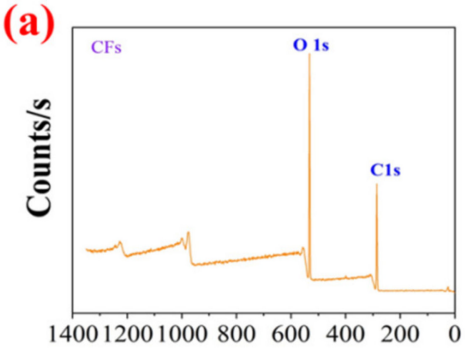

Binding energy/eV

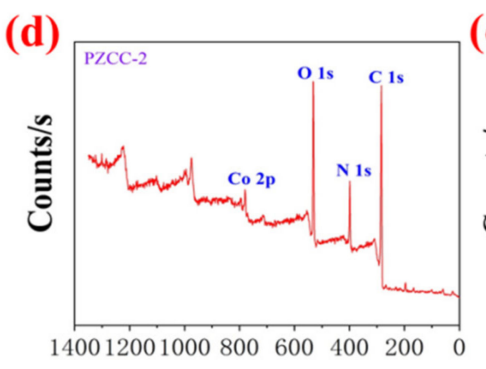

Binding energy/eV

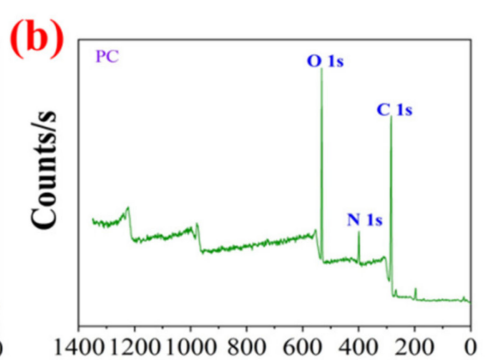

Binding energy/eV

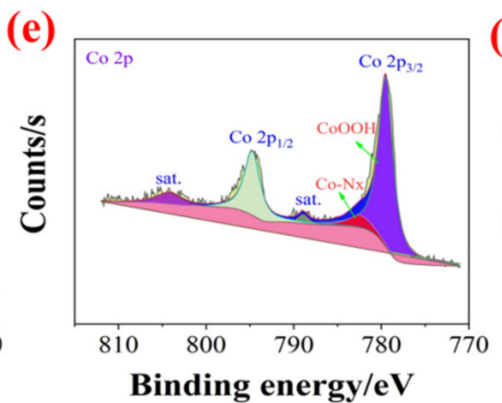

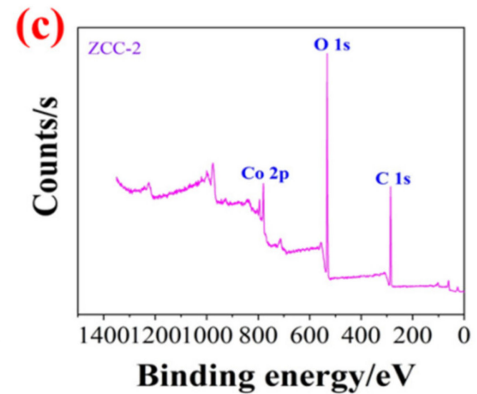

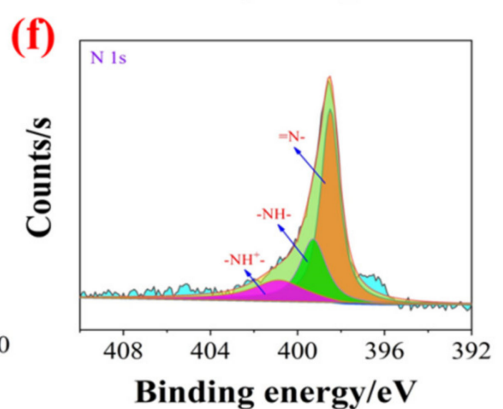

Figure 4. XPS survey spectrum of CFs (a), PC (b), ZCC-2 (c), and PZCC-2 (d). High-resolution XPS of Co 2p (e) and N 1s (f) based on ZCC-2 and PZCC-2.

\subsection{Evaluation of Electrochemical Performance}

In the three-electrode system, the CV and GCD tests were carried out in $0.6 \mathrm{M} \mathrm{H}_{2} \mathrm{SO}_{4}$ electrolyte over the potential window of $(-0.2)-0.6 \mathrm{~V}$ to evaluate the capacitance performance of hybrid electrode materials. As shown in Figure 5, the CV curves of PC, PZCC-1, and PZCC-2 present spindle shapes at higher scan rates, suggesting that the electrode material is not the only existence of electric double layer capacitance behavior. Moreover, the curves of PZCC-1 and PZCC-2 electrode materials were more rectangular than that of PC, indicating a lower charge transfer resistance, which is beneficial to obtain better 
electrochemical capacitance behavior. This opinion is also confirmed in EIS curves. The specific capacitance of electrode materials at different scan rates ranging from 5 to $50 \mathrm{mV} \cdot \mathrm{s}^{-1}$ are obtained via integrating $\mathrm{CV}$ curves. The result shows that the specific capacitance of PC is $164.41,117.64,82.78,68.53,59.38$, and $52.33 \mathrm{~F} \cdot \mathrm{g}^{-1}$. The specific capacitance of PZCC-1 is $346.45,308.59,247.01,205.72,174.77$, and $95.92 \mathrm{~F} \cdot \mathrm{g}^{-1}$. The specific capacitance of PZCC-2 is 462.65, 356.99, 267.42, 211.04, 173.12, and 147.03 F.g ${ }^{-1}$. The PZCC-2 possesses a higher capacitance behavior than that of PC electrode material. This may be attributed to the more rapid charge transfer at the electrode/electrolyte interface, or the more efficient electrochemical behavior of the interface due to the change of the morphology and structure of PPy itself. As described above, GCD tests were also performed in order to study the capacitance performance of the electrode materials. As shown in Figure 6, the charging/discharging curves of all electrode materials show certain symmetry, indicating the reversibility of electrode materials. According to the various current densities of 0.2 , $0.5,1,2$, and $3 \mathrm{~A} \cdot \mathrm{g}^{-1}$, we calculated the capacitance of electrode materials. The specific capacitance of PC is $308.75,228.31,151.5,76.75$, and $55.87 \mathrm{~F} \cdot \mathrm{g}^{-1}$, the specific capacitance of PZCC-1 is 618.95, 500.56, 427.75, 345.00, and $304.88 \mathrm{~F} \cdot \mathrm{g}^{-1}$, and the specific capacitance of PZCC-2 is $696.65,553.88,461.88,379.25$, and $333.75 \mathrm{~F} \cdot \mathrm{g}^{-1}$, respectively. Besides, the comparative CV and GCD profiles of PC, PZCC-1, and PZCC-2 electrode materials at a scan rate of $5 \mathrm{mV}^{-1}$ and a current density of $0.2 \mathrm{~A} \cdot \mathrm{g}^{-1}$ are shown in Figure 7 , which can make it easier to see the significant differences and different reaction systems that also affect the PPy hybrid electrode materials. Compared to other CPs-based composites [47-54], the prepared electrode has better specific capacitance, which shows that this method is superior. The results indicate that the incorporation of ZIF-67 derived oxyhydroxide can improve the interface between CFs and PPy, which is beneficial to anchor the electrode material for more excellent electrochemical performance.

(a)

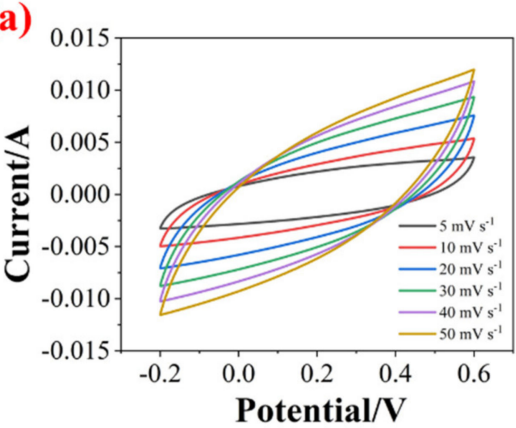

(c)

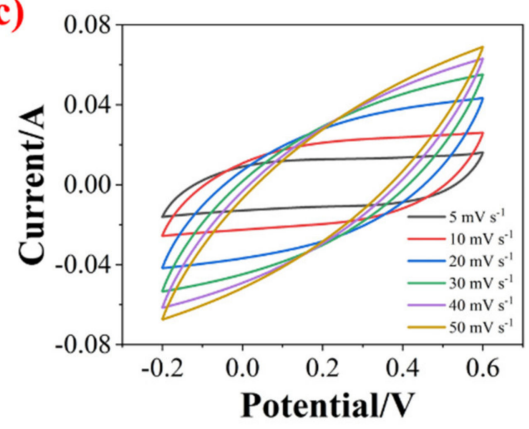

(b)

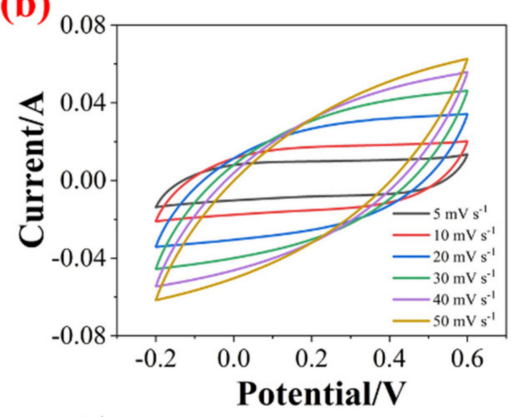

(d)

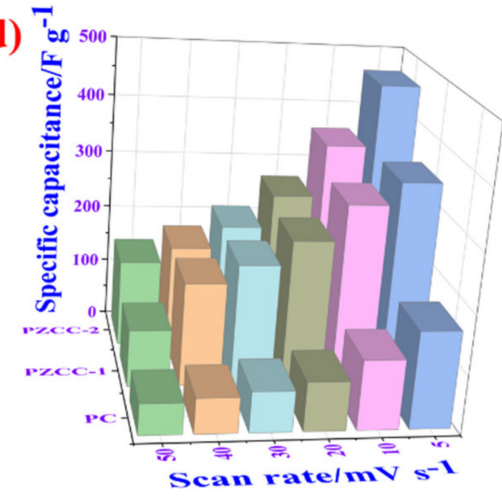

Figure 5. CV profiles of PC (a), PZCC-1 (b), and PZCC-2 (c) electrodes recorded using different scan rates of $5,10,20,30,40$, and $50 \mathrm{mV} \cdot \mathrm{s}^{-1}$, and (d) specific capacitance of PC, PZCC-1, and PZCC-2 at different densities of $5,10,20,30,40$, and $50 \mathrm{mV} \cdot \mathrm{s}^{-1}$. 

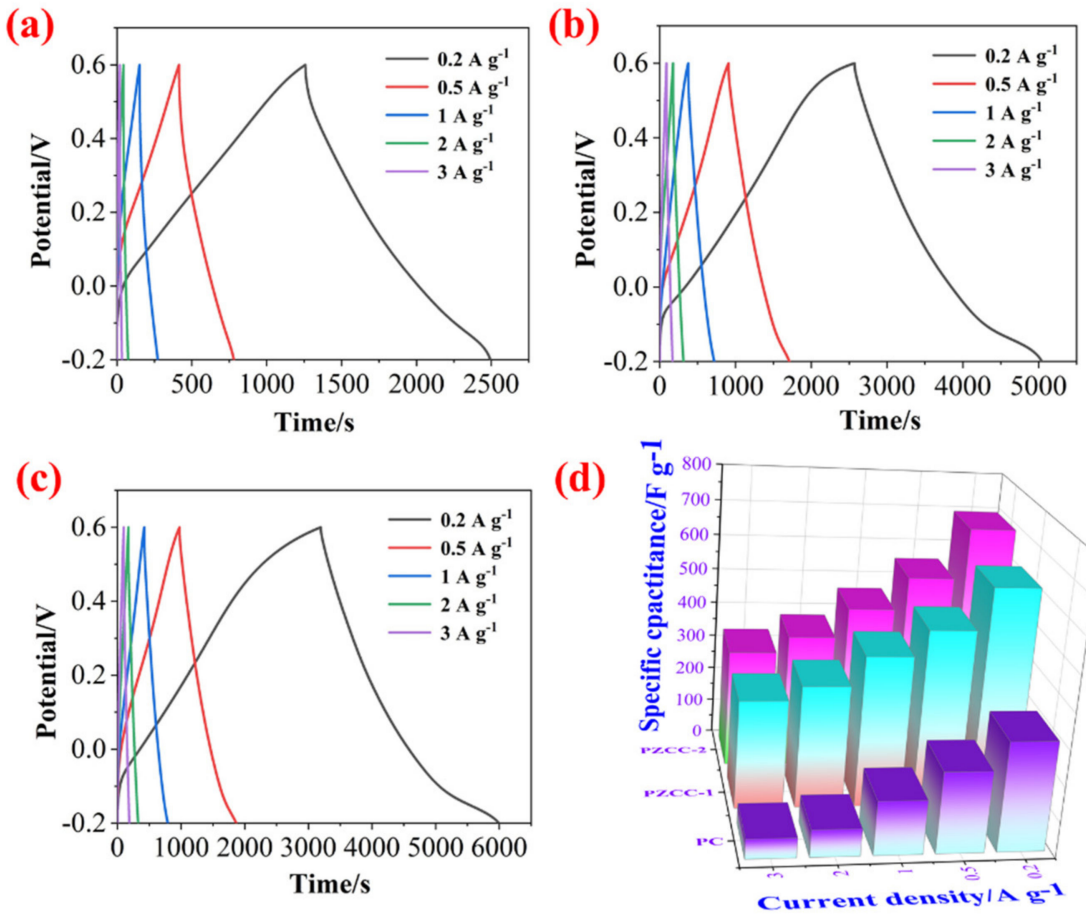

Figure 6. GCD profiles of PC (a), PZCC-1 (b), and PZCC-2 (c) electrodes at different current densities of $0.2,0.5,1,2$, and $3 \mathrm{~A} \cdot \mathrm{g}^{-1}$. (d) Comparative profiles of specific capacitance for PC, PZCC-1, and PZCC-2.

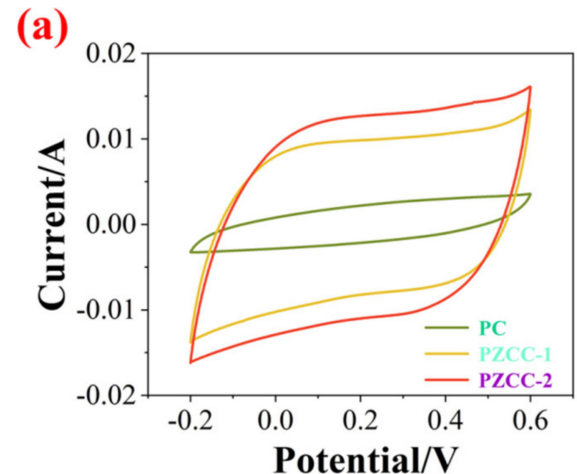

(b)
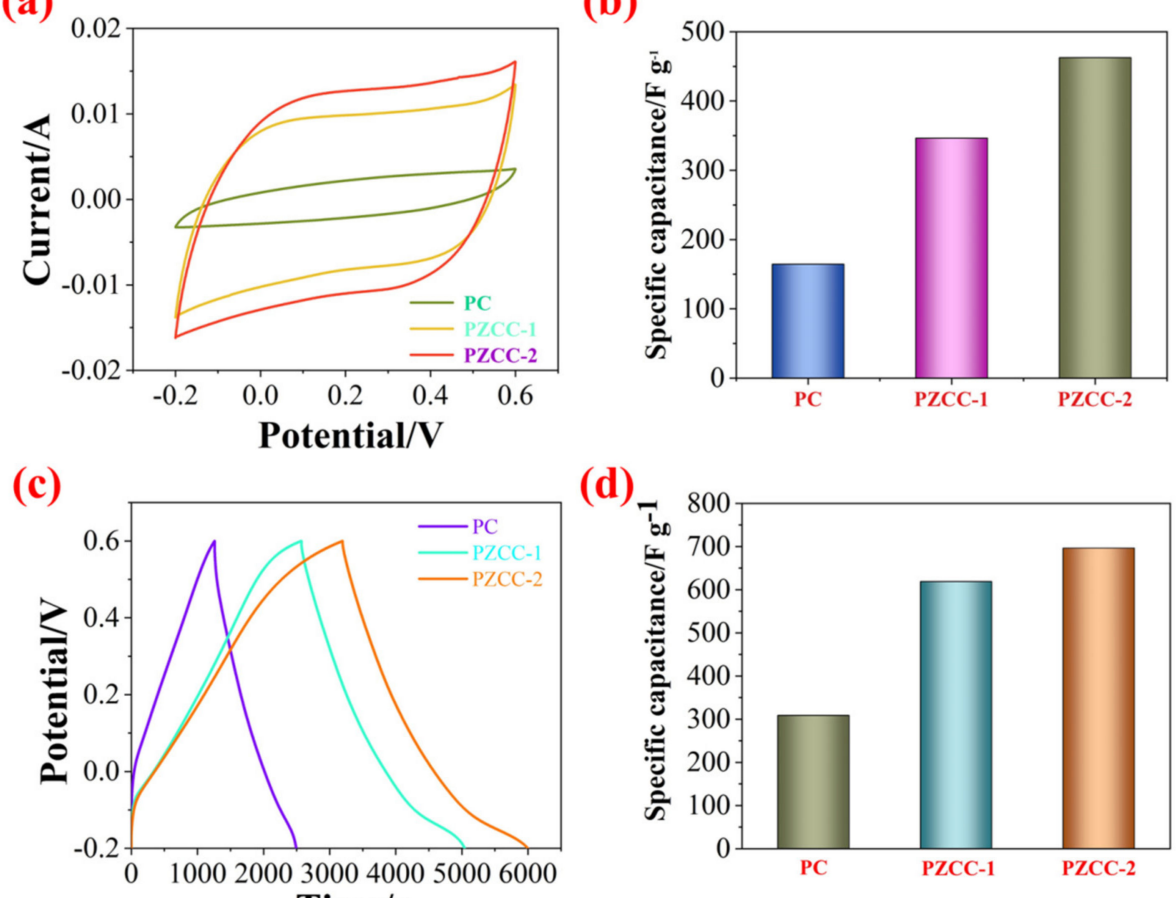

(d)

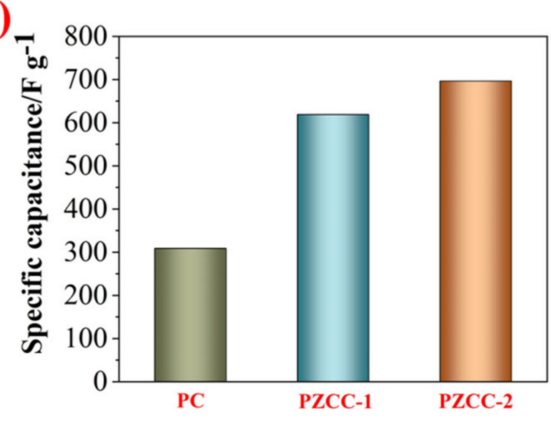

Figure 7. (a) Comparative CV profiles of PC, PZCC-1, and PZCC-2 at a scan rate of $5 \mathrm{mV} \cdot \mathrm{s}^{-1}$, (b) specific capacitance of PC, PZCC-1, and PZCC-2 at a current density of $5 \mathrm{mV}^{-1}$, (c) comparative GCD profiles of PC, PZCC-1, and PZCC-2 at a current density of $0.2 \mathrm{~A} \cdot \mathrm{g}^{-1}$, and (d) specific capacitance of PC, PZCC-1, and PZCC-2 at a current density of $0.2 \mathrm{~A} \cdot \mathrm{g}^{-1}$.

To further explore the electrochemical reaction kinetics of electrode materials, in this paper, we took PZCC-2 as an example to analyze its CV curves. The total capacitance 
can be divided into surface capacitance and diffusion-controlled contribution at a certain scanning rate according to the following formula:

$$
i=k_{1} v+k_{2} v^{1 / 2}
$$

where $k_{1} v$ and $k_{2} v$ are attributed to surface capacitive effect and diffusion-controlled process, respectively. Here, when $k_{2}$ is zero, we obtain $k_{1}$ value via calculating the current and scan rate ratio of $\mathrm{CV}$ curve at different scan rates. Then, the surface capacitance contributions of $\mathrm{CV}$ curves are integrated to obtain the contribution ratio of surface capacitance and diffusion-controlled capacitance at a different scan rate as shown in Figure 8. The surface capacitance contributions are $29.66 \%, 36.13 \%, 48.24 \%, 61.13 \%, 74.51 \%$, and $87.74 \%$, indicating that the capacitance is mainly reflected in the surface capacitance behavior at high scan rate, it is also difficult to reflect the real capacitance behavior of electrode material.

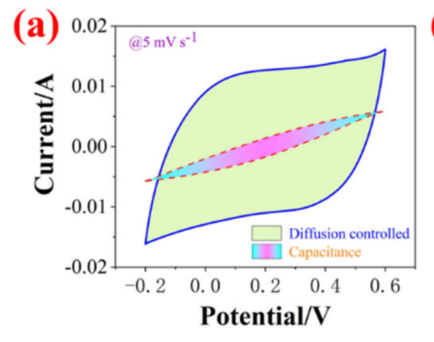

(e)

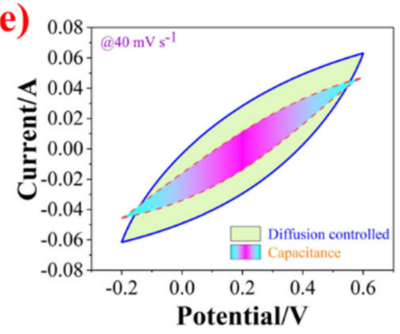

(b)

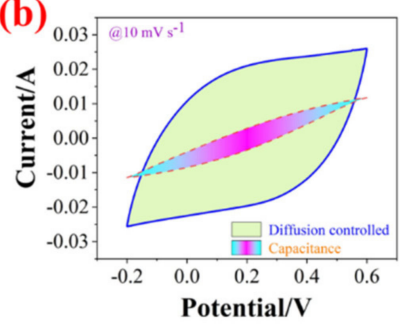

(f)

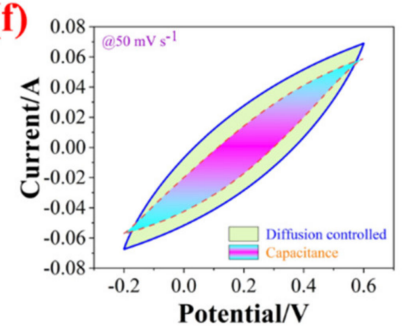

(c)

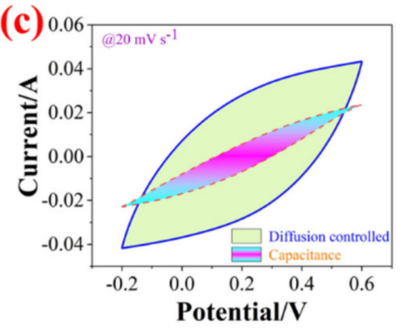

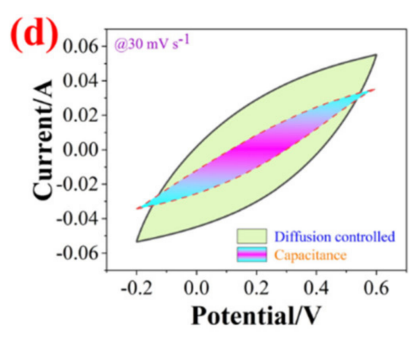

(g)

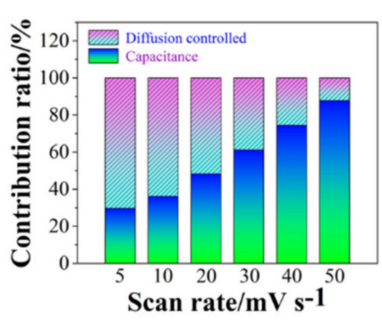

Figure 8. Diffusion controlled and capacitance CV profiles for PZCC-2 electrodes at different scan rates of 5, 10, 20, 30, 40, and $50 \mathrm{mV} \cdot \mathrm{s}^{-1}(\mathbf{a}-\mathbf{f})$, and $(\mathrm{g})$ contribution ratio of diffusion controlled and capacitance for PZCC-2 electrode material at different scan rates of $5,10,20,30,40$, and $50 \mathrm{mV} \cdot \mathrm{s}^{-1}$.

The EIS measurements demonstrate the far better conductivity of PZCC-1 and PZCC-2 than that of PC electrode materials, as shown in Figure 9a, and we also simulated the EIS plots based on it. The result is shown in Figure 9b, demonstrating that the electrochemical process of electrode materials includes three parts of equivalent series resistance (ESR), charge transfer resistance (Rct), and Warburg (W) diffusion. From EIS plots, the resistance value of PC is about $5.9 \Omega$, which is higher than those of PZCC-1 $(\sim 2.8 \Omega)$, PZCC-2 $(\sim 2.5 \Omega)$ and the previous study $(\sim 3.5 \Omega)$ [36], indicating faster electron transfer of PZCC-2 electrode material at the interface between electrode and electrolyte. The straight line at the low frequency of PZCC-2 is closer to the Y-axis, suggesting better ion diffusion from the electrolyte to the electrode. All the results support the better specific capacitance performance of PZCC-2 than that of PC electrode material.

The service life is very important in the evaluation of the electrochemical performance of the electrode materials. The electric double layer electrode material has an excellent cyclic stability due to its own energy storage characteristics. For the CPs@CFs pseudo-capacitance electrode material, the continuous expansion or collapse of the conductive polymer will result in the poor cycle stability of the composite material during the electrochemical cycle, which is not conducive to its further processing and utilization. Here, we use ZIF-67 as the precursor to prepare ZIF-67-derived cobalt oxyhydroxide@CFs composite materials by further oxidation, and then load the PC conductive polymer on the composite material via the in-situ method. The result is shown in Figure 9c, the capacitance retention of 
PZCC-2 hybrid electrode material (92.56\%) is higher than that of PC electrode materials $(72.19 \%)$, suggesting that the introduction of ZIF-67-derived cobalt oxyhydroxide improved the intrinsic resistance and interface charge transfer. The EIS plots of PC and PZCC-2 electrodes before and after 1000 cycles are shown in Figure 9d,e. The equivalent series resistances of PC and PZCC-2 electrodes after 1000 cycles are about $3.9 \Omega$ and $6.8 \Omega$, which are higher than those of PC and PZCC-2 electrodes before cycle. Similarly, the electrodes have higher charge transfer resistance and longer Weber liner, which also explains the decline of capacitance retention for PC and PZCC-2 electrodes.

(a)
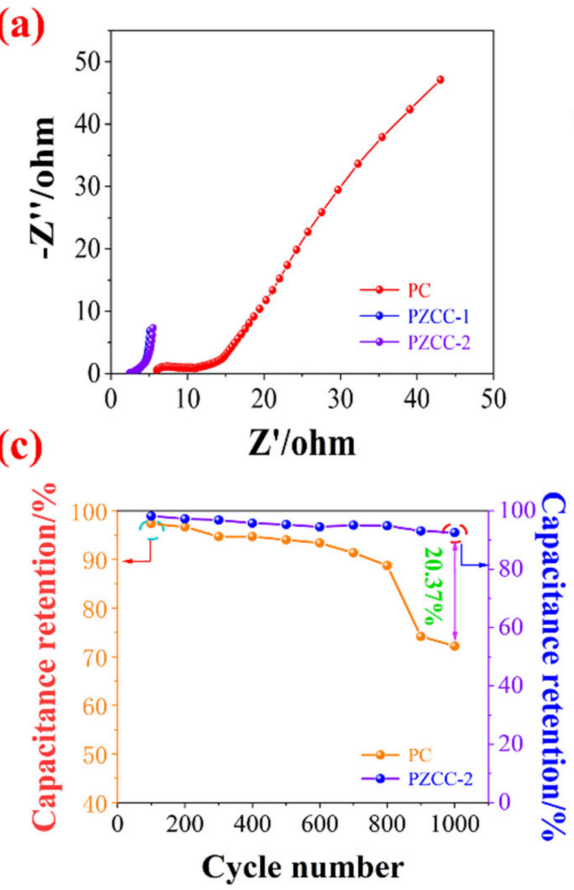

(b)

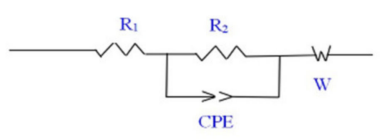

(d)

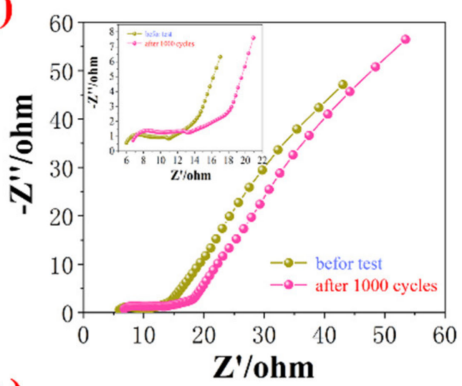

(e)

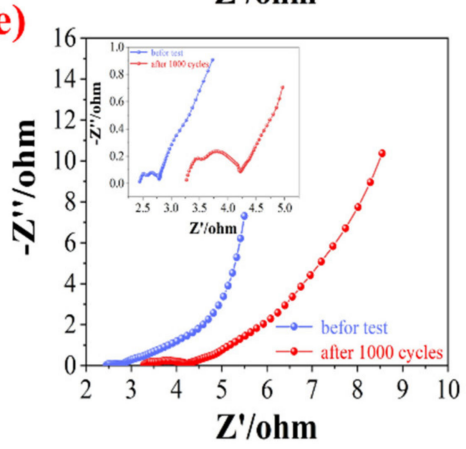

Figure 9. (a) Comparative Nyquist plots of PC, PZCC-1, and PZCC-2 electrode materials, (b) EIS circuit of electrode materials, (c) capacitance retention of PC and PZCC-2 electrode materials, and (d,e) Nyquist plots of PC and PZCC-2 electrode materials before and after 1000 cycles.

To investigate the electrochemical performance of PZCC-2-SCs, the CV and GCD were performed at various scan rates and current densities over the potential window of $0-0.8 \mathrm{~V}$, and the corresponding results are shown in Figure 10. The specific capacitance is $234.50,175.19,104.25,74.49,56.30$, and $35.03 \mathrm{mF} \cdot \mathrm{cm}^{-2}$. Then, the volumetric energy density (E) and power density were calculated according to the equations of (4) and (5). The PZCC-2-SCs can provide an energy density of $45.51 \mathrm{mWh} \mathrm{cm}^{-3}$ at a power density of $174.67 \mathrm{~mW} \mathrm{~cm}^{-3}$, which is higher than previous report [53,54], suggesting the potential application in energy storage area.

In conclusion, the PPy@ZIF-67 derived cobalt oxyhydroxide@CFs hybrid electrode material can be applied in energy storage field for the following reasons. Firstly, CFs as flexible substrate materials are the most abundant resource on earth, and have excellent characteristics, such as flexibility, porous structures, and wettability, etc. Secondly, the PPy conductive polymer possesses superior conductivity and redox pseudo-capacitance features. Thirdly, the introduction of ZIF-67-derived cobalt oxyhydroxide is beneficial to anchor PPy via the chemical bond force of $\mathrm{Co}-\mathrm{Nx}$, which can improve the intrinsic resistance and interface charge transfer, which makes PPy@CFs composites have better specific capacitance and cyclic stability. 
(a)

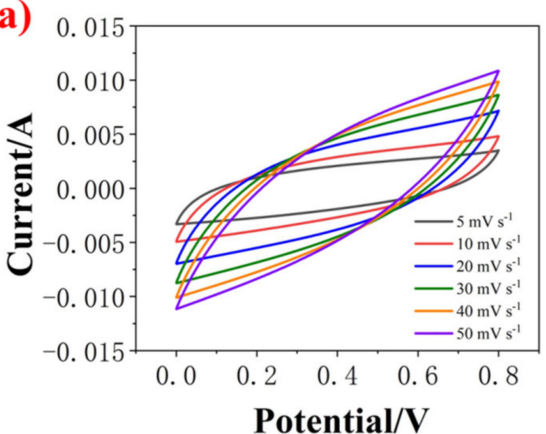

(c)

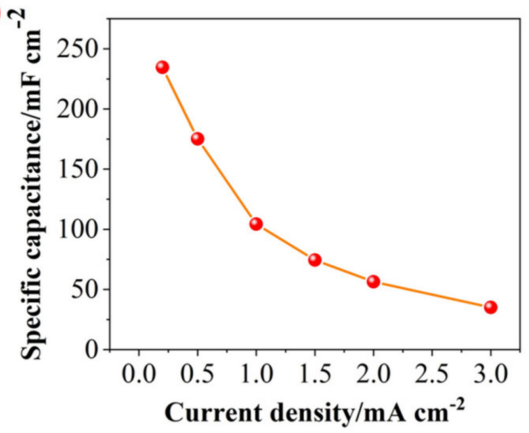

(b)

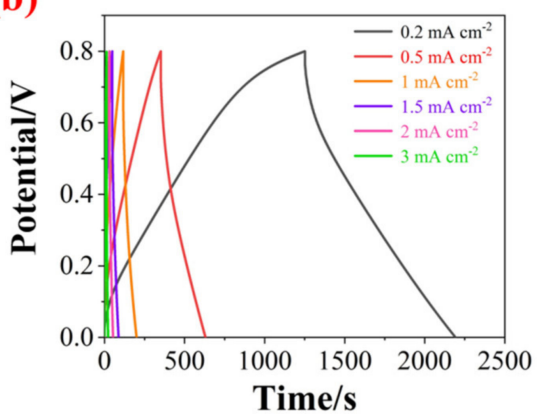

(d)

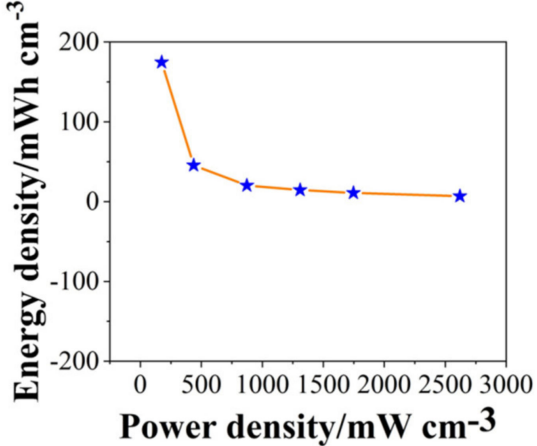

Figure 10. (a) CV curves of supercapacitors (SCs) based on PZCC-2 electrode materials at various scan rates from 5 to $50 \mathrm{mV} \mathrm{s}^{-1}$, (b) GCD curves SCs based on PZCC-2 electrode materials at different current densities from 0.2 to $3 \mathrm{~mA} \mathrm{~cm}{ }^{-2}$, (c) specific capacitance of SCs at different current densities, and (d) energy density-power density curves of SCs.

\section{Conclusions}

In summary, we designed a feasible method to prepare ZIF-67-derived cobalt oxyhydroxide with high crystallinity and nanoscale for enhancing PPy@CFs composite. The incorporation of ZIF-67-derived cobalt oxyhydroxide in composite improves the hyrdrophilicity and conductivity (resistance value of $\sim 2.5 \Omega$ ) of hybrid electrode, and hence obtains higher specific capacitance $\left(696.65 \mathrm{~F} \cdot \mathrm{g}^{-1}\right)$ and capacitance retention $(92.56 \%)$. Besides, The PZCC-SC can provide an energy density of $45.51 \mathrm{mWh} \cdot \mathrm{cm}^{-3}$ at a power density of $174.67 \mathrm{~mW} \cdot \mathrm{cm}^{-3}$, which is higher than that of previous report. This work demonstrated that the modification of PPy@CFs electrode with ZIF-67-derived cobalt oxyhydroxide could be an effective approach to fabricate $\mathrm{CPs} @ \mathrm{CFs}$ electrodes with excellent performance, which will facilitate their application in energy storage area.

Author Contributions: S.Y. and X.Q. designed the experiments; S.Y. and X.A. conducted the experiments; S.Y. and X.Q. analyzed the data; S.Y. and X.Q. wrote the paper. All authors discussed the results and contributed to the improvement of the final text of the paper. All authors have read and agreed to the published version of the manuscript.

Funding: This work was supported by the National Natural Science Foundation of China (grant no. 31770620), and Fundamental Research Funds for the Central Universities (grant no. 2572019AB09).

Institutional Review Board Statement: Not applicable.

Informed Consent Statement: Not applicable.

Data Availability Statement: The authors confirm that the data supporting the findings of this study are available within the article.

Conflicts of Interest: The authors declare no conflict of interest. 


\section{References}

1. Liu, Z.; Li, H.; Zhu, M.; Huang, Y.; Tang, Z.; Pei, Z.; Wang, Z.; Shi, Z.; Liu, J.; Huang, Y.; et al. Towards wearable electronic devices: A quasi-solid-state aqueous lithium-ion battery with outstanding stability, flexibility, safety and breathability. Nano Energy 2018, 44, 164-173. [CrossRef]

2. Jiao, Y.; Liu, Y.; Yin, B.; Zhang, S.; Qu, F.; Wu, X. Hybrid $\alpha-\mathrm{Fe}_{2} \mathrm{O}_{3} @ \mathrm{NiO}$ heterostructures for flexible and high performance supercapacitor electrodes and visible light driven photocatalysts. Nano Energy 2014, 10, 90-98. [CrossRef]

3. $\mathrm{Wu}, \mathrm{X}$; Yao, S. Flexible electrode materials based on $\mathrm{WO}_{3}$ nanotube bundles for high performance energy storage devices performance energy storage devices. Nano Energy 2017, 42, 143-150. [CrossRef]

4. Liu, J.; Zheng, M.; Shi, X.; Zeng, H.; Xia, H. Amorphous FeOOH quantum dots assembled mesoporous film anchored on graphene nanosheets with superior electrochemical performance for supercapacitors. Adv. Funct. Mater. 2016, 26, 919-930. [CrossRef]

5. Liu, J.; Xu, X.; Yu, J.; Hong, J.; Chen, D. Facile construction of 3D porous carbon nanotubes/polypyrrole and reduced graphene oxide on carbon nanotube fiber for high-performance asymmetric supercapacitors. Electrochim. Acta 2019, 314, 9-19. [CrossRef]

6. Wei, B.; Liang, H.; Wang, R.; Zhang, D.; Qi, Z.; Wang, Z. One-step synthesis of graphitic- $\mathrm{C}_{3} \mathrm{~N}_{4} /$ ZnS composites for enhanced supercapacitor performance. J. Energy Chem. 2018, 27, 472-477. [CrossRef]

7. Liu, C.; Yan, X.; Hu, F.; Gao, G.; Wu, G.; Yang, X. Toward superior capacitive energy storage: Recent advances in pore engineering for dense electrodes. Adv. Mater. 2018, 30, 1705713. [CrossRef]

8. Xu, W.; Jiang, Z.; Yang, Q.; Huo, W.; Javed, M.S.; Li, Y.; Huang, L.; Gu, X.; Hu, C. Approaching the lithium-manganese oxides energy storage limit with $\mathrm{Li}_{2} \mathrm{MnO}_{3}$ nanorods for high-performance supercapacitor. Nano Energy 2018, 43, 168-176. [CrossRef]

9. Peter, S.; Lyczko, N.; Gopakumar, D.; Maria, H.J.; Nzihou, A.; Thomas, S. Chitin and chitosan based composites for energy and environmental applications: A Review. Waste Biomass Valoriz. 2020. [CrossRef]

10. Huang, G.; Geng, Q.; Xing, B.; Liu, Y.; Zhang, C. Manganous nitrate-assisted potassium hydroxide activation of humic acid to prepare oxygen-rich hierarchical porous carbon as high-performance supercapacitor electrodes. J. Power Sources 2019, $449,227506$. [CrossRef]

11. Liu, N.; Pan, Z.; Ding, X.; Yang, J.; Xu, G.; Li, L.; Wang, Q.; Liu, M.; Zhang, Y. In-situ growth of vertically aligned nickel cobalt sulfide nanowires on carbon nanotube fibers for high capacitance all-solid-state asymmetric fiber-supercapacitors. J. Energy Chem. 2020, 41, 221-227. [CrossRef]

12. Yan, S.; Luo, S.; Feng, J.; Li, P.; Guo, R.; Wang, Q.; Zhang, Y.; Liu, Y.; Bao, S. Rational design of flower-like FeCo $\mathrm{S}_{4} / \mathrm{reduced}$ graphene oxide films: Novel binder-free electrodes with ultra-high conductivity flexible substrate for high-performance all-solidstate pseudocapacitor. Chem. Eng. J. 2020, 381, 122695. [CrossRef]

13. Ramesh, P.; Amalraj, S.; Arunachalam, P.; Gopiraman, M.; Al-Mayouf, A.M.; Vasanthkumar, S. Covalent intercalation of hydrazine derived graphene oxide as an efficient 2D material for supercapacitor application. Synth. Met. 2021, 272, 116656. [CrossRef]

14. Nie, G.; Zhao, X.; Jiang, J.; Luan, Y.; Shi, J.; Liu, J.; Kou, Z.; Wang, J.; Long, Y. Flexible supercapacitor of high areal performance with vanadium/cobalt oxides on carbon nanofibers as a binder-free membrane electrode. Chem. Eng. J. 2020, $402,126294$. [CrossRef]

15. Naushad, M.; Ahamad, T.; Ubaidullah, M.; Ahmed, J.; Ghafar, A.A.; Al-Sheetan, K.M.; Arunachalam, P. Nitrogen-doped carbon quantum dots (N-CQDs) $/ \mathrm{Co}_{3} \mathrm{O}_{4}$ nanocomposite for high performance supercapacitor. J. King Saud Univ. Sci. 2021, $33,101252$. [CrossRef]

16. Singal, S.; Joshi, A.; Singh, G.; Sharma, R.K. Dual approach of antimonene hybridization and hierarchical structuration to expose more active sites for improved charge storage characteristics of $\mathrm{VS}_{4}$. J. Power Sources 2020, 475, 228669. [CrossRef]

17. Abdah, M.A.A.M.; Azman, N.H.N.; Kulandaivalu, S.; Sulaiman, Y. Review of the use of transition-metal-oxide and conducting polymer-based fibres for high-performance supercapacitors. Mater. Des. 2020, 186, 108199. [CrossRef]

18. Arunachalam, P. Polymer-Based Nanocomposites for Energy and Environmental Applications; Woodhead Publishing: Cambridge, UK; Shaston, UK, 2018; pp. 185-203.

19. Yang, X.; Biswas, S.K.; Han, J.; Tanpichai, S.; Li, M.; Chen, C.; Zhu, S.; Das, A.K.; Yano, H. Surface and interface engineering for nanocellulosic advanced materials. Adv. Mater. 2020, 2002264. [CrossRef]

20. Zhang, Y.; Wang, Y.; Cheng, T.; Lai, W.; Pang, H.; Huang, W. Flexible supercapacitors based on paper substrates: A new paradigm for low-cost energy storage. Chem. Soc. Rev. 2015, 44, 5181-5199. [CrossRef]

21. Xiao, B.; Huang, Q.; Chen, H.; Chen, X. A fractal model for capillary flow through a single tortuous capillary with roughened surfaces in fibrous porous media. Fractals 2021, 29, 2150017. [CrossRef]

22. Liang, M.; Fu, C.; Xiao, B.; Luo, L.; Wang, Z. A fractal study for the effective electrolyte diffusion through charged porous media. Int. J. Heat Mass Transfer 2019, 137, 365-371. [CrossRef]

23. Dong, C.; Yu, X.; Zhang, Y.; Huang, L.; Li, J.; Wu, Y.; Liu, Z. Correction: An ionic liquid-modified RGO/polyaniline composite for high-performance flexible all-solid-state supercapacitors. Chem. Commun. 2020, 56, 12255. [CrossRef]

24. Wang, Y.; Chen, F.; Liu, Z.; Tang, Z.; Yang, Q.; Zhao, Y.; Du, S.; Chen, Q. A highly elastic and reversibly stretchable all-polymer supercapacito. Angew. Chem. Int. Ed. 2019, 58, 15707-15711. [CrossRef]

25. Tebyetekerwa, M.; Yang, S.; Peng, S.; Xu, Z.; Shao, W.; Pan, D.; Ramakrishna, S.; Zhu, M. Unveiling polyindole: Freestanding aselectrospun polyindole nanofibers and polyindole/carbon nanotubes composites as enhanced electrodes for flexible all-solid-state supercapacitors. Electrochim. Acta 2017, 247, 400-409. [CrossRef] 
26. Liu, Y.; Murtaza, I.; Ahmed, S.; Meng, H. Interfacial modification for heightening the interaction between PEDOT and substrate towards enhanced flexible solid supercapacitor performance. Chem. Eng. J. 2019, 379, 12232. [CrossRef]

27. Sun, J.; Huang, Y.; Fu, C.; Wang, Z.; Huang, Y.; Zhu, M.; Zhi, C.; Hu, H. High-performance stretchable yarn supercapacitor based on PPy@CNTs@urethane elastic fiber core spun yarn. Nano Energy 2016,27, 230-237. [CrossRef]

28. Liu, Y.; Hu, P.; Liu, H.; Song, J.; Umar, A.; Wu, X. Toward a high performance asymmetric hybrid capacitor by electrode optimization. Inorg. Chem. Front. 2019, 6, 2824-2831. [CrossRef]

29. Rosas-Laverde, N.M.; Pruna, A.I.; Busquets-Mataix, D. Graphene oxide-polypyrrole coating for functional ceramics. Nanomaterials 2020, 10, 1188. [CrossRef]

30. Wei, D.; Zhu, J.; Luo, L.; Huang, H.; Yu, X. Fabrication of poly(vinyl alcohol)-graphene oxide-polypyrrole composite hydrogel for elastic supercapacitors. J. Mater. Sci. 2020, 55, 11779-11791. [CrossRef]

31. Boota, M.; Anasori, B.; Voigt, C.; Zhao, M.; Barsoum, M.W.; Gogotsi, Y. Pseudocapacitive electrodes produced by oxidant-free polymerization of pyrrole between the layers of 2D titanium carbide (MXene). Adv. Mater. 2016, 28, 1517-1522. [CrossRef] [PubMed]

32. Tong, L.; Jiang, C.; Cai, K.; Wei, P. High-performance and freestanding PPy $/ \mathrm{Ti}_{3} \mathrm{C}_{2} \mathrm{~T}_{\mathrm{x}}$ composite film for flexible all-solid-state supercapacitors. J. Power Sources 2020, 465, 228267. [CrossRef]

33. Abdah, M.A.A.M.; Rahman, N.A.; Sulaiman, Y. Ternary functionalised carbon nanofiber/polypyrrole/manganese oxide as high specific energy electrode for supercapacitor. Ceram. Int. 2019, 45, 8433-8439. [CrossRef]

34. Zhao, P.; Wang, N.; Yao, M.; Ren, H.; Hu, W. Hydrothermal electrodeposition incorporated with CVD-polymerisation to tune $\mathrm{PPy} @ \mathrm{MnO}_{2}$ interlinked core-shell nanowires on carbon fabric for flexible solid-state asymmetric supercapacitors. Chem. Eng. J. 2020, 380, 122488. [CrossRef]

35. Peng, S.; Fan, L.; Wei, C.; Liu, X.; Zhang, H.; Xu, W.; Xu, J. Flexible polypyrrole/copper sulfide/bacterial cellulose nanofibrous composite membranes as supercapacitor electrodes. Carbohydr. Polym. 2017, 157, 344-352. [CrossRef] [PubMed]

36. Yang, S.; Sun, L.; An, X.; Qian, X. Construction of flexible electrodes based on ternary polypyrrole@cobalt oxyhydroxide/cellulose fiber composite for supercapacitor. Carbohydr. Polym. 2020, 229, 115455. [CrossRef] [PubMed]

37. An, Y.; Yang, Y.; Hu, Z.; Guo, B.; Wang, X.; Yang, X.; Zhang, Q.; Wu, H. High-performance symmetric supercapacitors based on carbon nanosheets framework with graphene hydrogel architecture derived from cellulose acetate. J. Power Sources 2017, 337, 45-53. [CrossRef]

38. Chen, M.; Wu, B.; Li, D. Core-shell structured cellulose nanofibers/graphene@ polypyrrole microfibers for all-solid-state wearable supercapacitors with enhanced electrochemical performance. Macromol. Mater. Eng. 2020, 305, 1900854. [CrossRef]

39. Ren, J.; Jiang, N.; Shang, K.; Lu, N.; Li, J.; Wu, Y. Synergistic degradation of trans-ferulic acid by water falling film dbd plasma coupled with cobalt oxyhydroxide: Performance and mechanisms. Chem. Eng. J. 2019, 372, 321-331. [CrossRef]

40. Cherusseri, J.; Kar, K.K. Hierarchical carbon nanopetal/polypyrrole nanocomposite electrodes with brush-like architecture for supercapacitors. Phys. Chem. Chem. Phys. 2016, 18, 8587-8597. [CrossRef] [PubMed]

41. Yuan, L.; Yao, B.; Hu, B.; Huo, K.; Chen, W.; Zhou, J. Polypyrrole-coated paper for flexible solid-state energy storage. Energy Environ. Sci. 2013, 6, 470-476. [CrossRef]

42. Wang, Z.; Xiong, X.; Long, Q.; Huang, Y. High-performance lithium storage in nitrogen-enriched carbon nanofiber webs derived from polypyrrole. Electrochim. Acta 2013, 106, 320-326. [CrossRef]

43. Hebeish, A.; Farag, S.; Sharaf, S.; Shaheen, T.I. Advancement in conductive cotton fabrics through in situ polymerization of polypyrrole-nanocellulose composites. Carbohydr. Polym. 2016, 151, 96-102. [CrossRef]

44. Lay, M.; González, I.; Tarrés, J.A.; Pellicer, N.; Bun, K.N.; Vilaseca, F. High electrical and electrochemical properties in bacterial cellulose/polypyrrole membranes. Eur. Polym. J. 2017, 91, 1-9. [CrossRef]

45. Shen, C.; Jie, S.; Chen, H.; Liu, Z. The Co-N-C catalyst synthesized with a hard-template and etching method to achieve well-dispersed active sites for ethylbenzene oxidation. Front. Chem. 2019, 7, 426. [CrossRef]

46. Biniak, S.; Szymanski, G.; Siedlewski, J.; Swiatkowski, A. The characterization of activated carbons with oxygen and nitrogen surface groups. Carbon 1997, 35, 1799-1810. [CrossRef]

47. Fu, X.; Li, T.; Qi, F.; Zhang, S.; Wen, J.; Shu, W.; Luo, P.; Zhang, R.; Hu, S.; Liu, Q. Designing high electrochemical surface area between polyaniline and hydrogel polymer electrolyte for flexible supercapacitors. Appl. Surf. Sci. 2020, 507, 145135. [CrossRef]

48. Tian, J.; Peng, D.; Wu, X.; Li, W.; Deng, H.; Liu, S. Electrodeposition of Ag nanoparticles on conductive polyaniline/cellulose aerogels with increased synergistic effect for energy storage. Carbohydr. Polym. 2017, 156, 19-25. [CrossRef] [PubMed]

49. Zhang, X.; Li, H.; Zhang, W.; Huang, Z.; Tsui, C.P.; Lu, C.; Chen, C.; Yang, Y. In-situ growth of polypyrrole onto bamboo cellulose-derived compressible carbon aerogels for high performance supercapacitors. Electrochim. Acta 2019, 301, 55-62. [CrossRef]

50. Zhuo, H.; Hu, Y.; Chen, Z.; Zhong, L. Cellulose carbon aerogel/PPy composites for high-performance supercapacitor. Carbohydr. Polym. 2019, 215, 322-329. [CrossRef] [PubMed]

51. Lay, M.; Àngels Pèlach, M.; Pellicer, N.; Tarrés, J.A.; Bun, K.N. Smart nanopaper based on cellulose nanofibers with hybrid PEDOT:PSS/polypyrrole for energy storage devices. Carbohydr. Polym. 2017, 165, 86-95. [CrossRef]

52. Kumar, N.; Ginting, R.T.; Kang, J.W. Flexible, large-area, all-solid-state supercapacitors using spray deposited PEDOT:PSS/reducedgraphene oxide. Electrochim. Acta 2018, 270,37-47. [CrossRef] 
53. Sheng, N.; Chen, S.; Yao, J.; Guan, F.; Zhang, M.; Wang, B.; Ji, Z.; Wu, P.; Wang, H. Polypyrrole@TEMPO-oxidized bacterial cellulose/reduced graphene oxide macrofibers for flexible all-solid-state supercapacitors. Biochem. Eng. J. 2019, 368, 1022-1032. [CrossRef]

54. Sun, C.; Li, X.; Zhao, J.; Cai, Z.; Ge, F. A freestanding polypyrrole hybrid electrode supported by conducting silk fabric coated with PEDOT:PSS and MWCNTs for high-performance supercapacitor. Electrochim. Acta 2019, 317, 42-51. [CrossRef] 